\title{
Theory and Practice of Neuromarketing: Analyzing Human Behavior in Relation to Markets
}

\author{
Kateřina Bočková ${ }^{1^{*}}$, Jana Škrabánková ${ }^{2}$, Michal Hanák ${ }^{3}$ \\ ${ }^{1}$ DTI University, Department of Management and Economics, Sládkovičova 553/20, 01841 Dubnica nad Váhom, Slovakia \\ ${ }^{2}$ University of Ostrava, Faculty of Education, Department of physics, Fráni Šrámka 3, 70900 Ostrava, Czech Republic \\ ${ }^{3}$ DTI University, Department of Didactics of Specialized Subjects, Sládkovičova 553/20, 01841 Dubnica nad Váhom, Slovakia
}

\begin{abstract}
The presented paper deals with a comprehensive interpretation of the term neuromarketing, as a discipline that applies neuroscientific methods to analyze and to understand human behavior in relation to markets and market exchanges. Due to the topic, this paper presents mainly secondary data, next the questionnaire is used. We state that neuromarketing is a discipline that applies neuroscientific methods to analyze and to understand human behavior in relation to the markets and market exchanges. Each of the neuromarketing techniques measures different data and suits different purposes, with a combination of the most reliable results. The interest in the theoretical research of neuromarketing focuses on the consumer decision-making process. One of the main benefits of neuromarketing is the potential to measure accurate, objective data that can be used to make informed decisions in management practice. However, it is currently only a complement to other areas of marketing and will be beneficial if it is used to obtain otherwise inaccessible data. We are convinced that the existence of the Neuromarketing Center in the ITI of the Olomouc agglomeration will be a significant contribution to the development of the neuromarketing theory.
\end{abstract}

\section{1- Introduction}

The human brain has fascinated professionals and the public since time immemorial. Despite long-standing interest, science has found more about its functioning in just the last few years than in its entire previous history, as stated in O'Connell et al. (2011) [1]. Hand in hand with the rapid rise of available knowledge of neuroscience, an effort is being made to use this knowledge to better estimate human behavior in various contexts. The concept of neuroculture, which is defined in Javor et al. (2013) [2] study, has taken on the role of neuroscience in areas others than health care. Marketing has become one of them. This created neuromarketing, a relatively young discipline that applies neuroscience methods to analyze and understand human behavior related to the market and to market exchanges [3].

Data obtained using medical techniques are used in neuromarketing in two ways. The first leads to the development of the theoretical knowledge about human economic behavior and is carried out mainly in academic research. It involves examining the course of a consumer's decision-making and the factors that influence him, such as the influence of the emotions, the choice of attention, or the role of sensory experiences. The second is the practical effort to use neuromarketing both to optimize marketing communication and to better understand the needs and desires of consumers, provided by quickly adapted marketing agencies to commercial customers. In this way, ads are improved or products are tested using neuromarketing. Probably the most promising offer of neuromarketing is the monitoring and the measurement of unconscious factors that affect human behavior in this area. These cannot be monitored by conventional marketing techniques. The offer is particularly attractive at a time when cognitive science has changed its previous

* CONTACT: Bockova@dti.sk

DOI: http://dx.doi.org/10.28991/esj-2021-01256

(C) 2021 by the authors. Licensee ESJ, Italy. This is an open access article under the terms and conditions of the Creative Commons Attribution (CC-BY) license (https://creativecommons.org/licenses/by/4.0/). 
attitude and declares that the vast majority of human decision-making takes place on an unconscious level, as confirmed by Damasio (2000) and Calne (2000) [4, 5]. At the same time, unlike other branches of marketing, neuromarketing offers insight into these unconscious decision-making processes. There is controversy over the scope of this insight. Especially in the popularization literature on the topic, we come across fascinating reports about the almost completed effort of neuromarketing to find a "shopping button" in the consumer's brain. In contrast, those who argue that neuromarketing is nothing more than the efforts of the scientists and marketing consultants involved to get rich by dazzling corporate clients with complex scientific knowledge [6].

The paper begins by introducing the concepts of marketing and neuroscience, while outlining the basis for the functioning of neural processes. The following is an offer of definitions of neuromarketing, from which we choose the most appropriate one. Related terms, neuroeconomics and consumer neuroscience are also explained. The work continues with an overview of the relatively short history of neuromarketing with the reasons for the innovation of classic marketing techniques. It also discusses neuroscientific methods. Subsequently, it deals with the analysis of the main theoretical findings, which the authors identified as the most important by studying the literature. Due to its academic context, this work is focused on them. It divides them according to the consumer's decision-making process. Then the work continues with a summary of the practical uses of neuromarketing. Finally, the arguments for and against the ethics of using medical methods for marketing purposes are evaluated.

\section{2- Material and Methods}

The aim of this paper is to objectively explain the basics of how neuromarketing works, to show what it offers, to discuss its current position, to evaluate its contribution to marketing and thus to lean towards one of the above views. It may be appropriate in the context of Czech literature on the topic, which currently consists mainly of journalisticpopularization titles. The secondary goal of the work is to provide an objective overview of the topic in Czech. In addition, another secondary goal is to present the results of a questionnaire survey, the aim of which was to determine whether there would be an interest in the services of a potentially existing Neuromarketing Center in the Czech Republic. Due to the current economic situation, we decided to place a potential Neuromarketing Center in the Olomouc agglomeration.

The Olomouc agglomeration is a metropolitan-type agglomeration; it belongs to the so-called ITI territorial units. It has 240 municipalities. The location of the agglomeration directly determines its role as a transport hub and a regional center of wider importance. The agglomeration is the seat of several companies that are major employers of this region. The territory of the Olomouc agglomeration is a compact and continuous area very strongly heterogeneous in terms of the demographic, social, economic, but also environmental and infrastructural characteristics. This creates a positive environment for the development of the agglomeration, especially in the connection with the implementation of large projects, which is undoubtedly the Neuromarketing Center. The impacts of the positive activities of the Neuromarketing Center could be of a national and higher significance. The basic characteristics of the Olomouc agglomeration already state that the agglomeration is suitable for the development of the high-tech sector, while we perceive the high-tech sector in accordance with the Eurostat methodology. We can classify the Neuromarketing Center among High-tech services, because the nature of its activities will make the Neuromarketing Center one of the research and development institutions in the field of technical, but also humanities and social sciences. Figure 1 below shows the procedure for processing the paper.

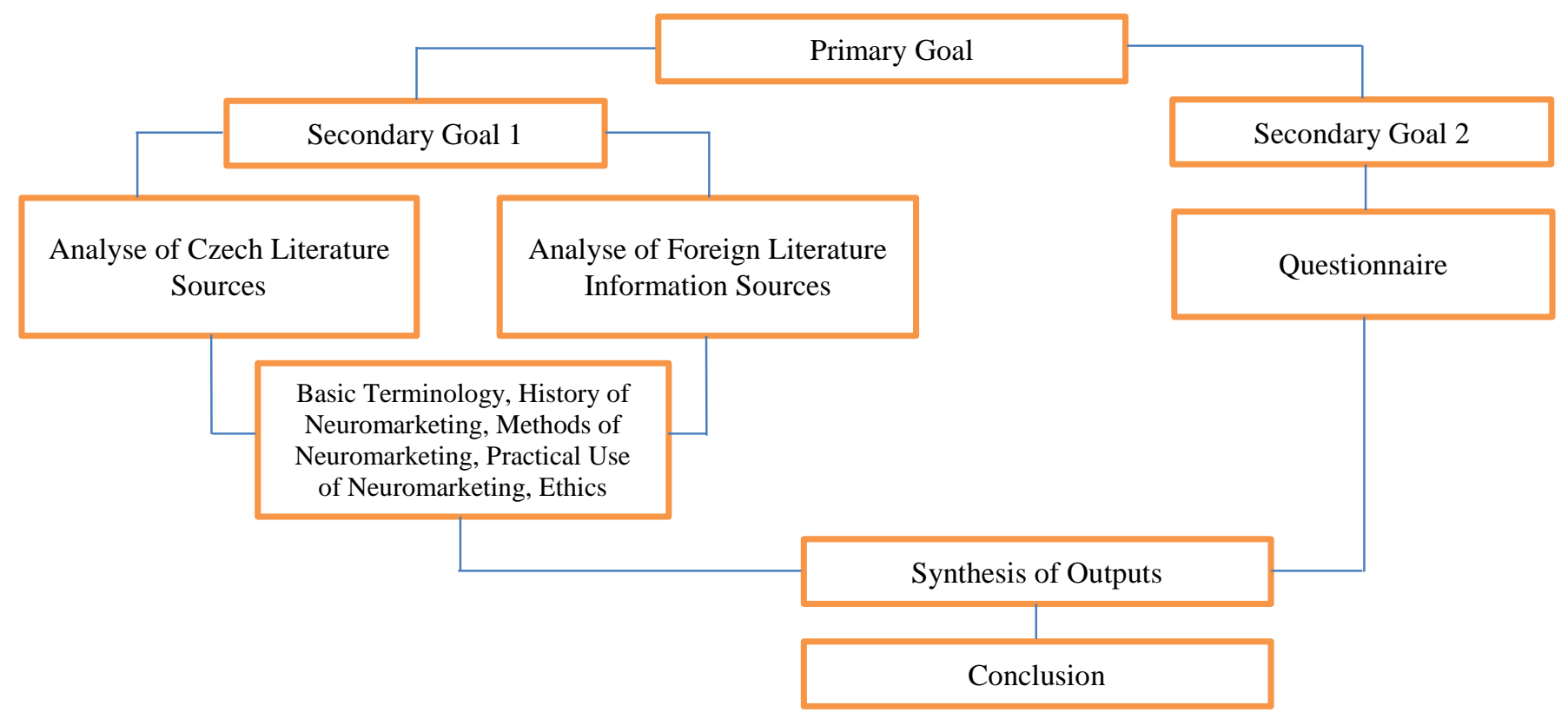

Figure 1. Flowchart of the research methodology. 


\section{2-1- Questionnaire Survey}

A questionnaire survey with the aim of finding out the interest in the services of the Neuromarketing Center was carried out in the period June - August 2020. The evaluation of the data was carried out in September 2020.

Table 1. Respondents by size of enterprises (size of enterprise was determined according to EU rules).

\begin{tabular}{|c|c|c|c|}
\hline & Characteristics of the company & $\begin{array}{c}\text { Number of responded } \\
\text { companies }\end{array}$ & Share in \% \\
\hline Micro-enterprise & $\begin{array}{l}\text { Micro-enterprises are defined as the } \\
\text { enterprises which employ fewer than } 10 \\
\text { persons and whose annual turnover or annual } \\
\text { balance sheet total does not exceed } 2 \text { million } \\
\text { EUR. }\end{array}$ & 405 & 21.8 \\
\hline Small enterprise & $\begin{array}{l}\text { A small enterprise is an enterprise which } \\
\text { employs fewer than } 50 \text { persons and whose } \\
\text { annual turnover or annual balance sheet total } \\
\text { does not exceed } 10 \text { million EUR. }\end{array}$ & 1092 & 58.8 \\
\hline Medium enterprise & $\begin{array}{l}\text { These are enterprises which employ fewer } \\
\text { than } 250 \text { persons and whose annual turnover } \\
\text { does not exceed } 50 \text { million EUR or whose } \\
\text { annual balance sheet total does not exceed } 43 \\
\text { million EUR. }\end{array}$ & 347 & 18.7 \\
\hline Large enterprise & $\begin{array}{l}\text { If a company is neither a micro, small nor } \\
\text { medium-sized enterprise according to the } \\
\text { above parameters, it is one of the large } \\
\text { enterprises. }\end{array}$ & 13 & 0.7 \\
\hline Total & & 1857 & 100 \\
\hline
\end{tabular}

In this three-month period, 2000 companies, organizations and institutions of the for-profit and non-profit sectors of all sizes, which are based in the Olomouc agglomeration, were addressed (see Table 1 and Table 2).

Table 2. Respondents according to the individual sections of the CZ-NACE

\begin{tabular}{|c|c|c|c|c|}
\hline $\begin{array}{c}\text { Name od } \\
\text { CZ-NACE }\end{array}$ & CZ-NACE & Name of CZ-NACE section & $\begin{array}{l}\text { Number of } \\
\text { respondents }\end{array}$ & $\begin{array}{c}\text { Share in } \\
\%\end{array}$ \\
\hline \multirow{3}{*}{ Industry } & $\mathrm{C}$ & Mining and quarrying & 5 & 0.2 \\
\hline & $\mathrm{D}$ & Manufacturing industry & 288 & 15.5 \\
\hline & $\mathrm{E}$ & Production and distribution of electricity, gas and water & 2 & 0.1 \\
\hline Construction & $\mathrm{F}$ & Construction & 208 & 11.2 \\
\hline Trade & G & $\begin{array}{l}\text { Trade, repair of motor vehicles and products for other } \\
\text { consumption and mainly household }\end{array}$ & 472 & 25.73 \\
\hline Hospitality & $\mathrm{H}$ & Accommodation and meals & 78 & 4.2 \\
\hline Transport & I & Transport, storage and communications & 71 & 3.8 \\
\hline Finance & $\mathrm{J}$ & Financial intermediation & 32 & 1.7 \\
\hline \multirow{5}{*}{ Services } & $\mathrm{K}$ & Real estate and renting activities, business activities & 65 & 3.5 \\
\hline & $\mathrm{L}$ & Public administration and defense, compulsory social security & 1 & 0.05 \\
\hline & M & Education & 98 & 5.3 \\
\hline & $\mathrm{N}$ & Health and social care, veterinary activities & 9 & 0.5 \\
\hline & $\mathrm{O}$ & Other public social and personal services & 524 & 28.2 \\
\hline \multirow{2}{*}{ Agriculture } & A & Agriculture, hunting, forestry & 4 & 0.02 \\
\hline & $\mathrm{B}$ & Fishing and angling & 0 & 0 \\
\hline Total & & & 1857 & 100 \\
\hline
\end{tabular}

A questionnaire was sent to the hands of a marketing worker via the e-mail address provided on the website of the company, organization or institution. The questionnaire contained 20 questions, 17 questions were closed with a choice of yes - no, 3 questions were open. The questions in the questionnaire found out whether the respondents know the concept of neuromarketing, individual techniques used in neuromarketing, the principles of neuromarketing. Subsequently, the respondents were introduced to the Neuromarketing Center, including future services that the Center can provide. Respondents then had the opportunity to comment on whether they are interested in such services, why they are interested in services, they could specify their interest. 
The return rate of the questionnaires was $92.8 \%$ (1857 relevant questionnaire replies were returned). The statistical distribution of respondents according to the size of the enterprise basically corresponds to the representation of the individual sizes of enterprises in the Czech national economy. From this point of view, we find the choice of respondents to be appropriate and relevant.

\section{3- Literature Review}

Neuromarketing itself is, of course, defined differently in the literature. Huber and Kenning (2008) [7] state that neuromarketing is "a subset of neuroeconomics that solves marketing problems through knowledge and methods of brain research." Wilson et al. (1993) [8] mention the definition of neuromarketing as "the application of neuroscience methods to advertising". McDowell and Dick (2013) [9] study speak of the neuromarketing as an "alternative to language-based research, which allows the knowledge of unconscious motives of action using biological measurements." Marci (2008) [10] describe neuromarketing as "an attempt to use neuroscientific understanding of the brain and emotions for advertising purposes." Marci (2008) [10] study briefly defines neuromarketing as "the application of neuroscience to marketing research". Javor et al. (2013) [2] express themselves about neuromarketing as "a discipline that uses neuroscientific methods to study consumer behavior and purchasing decisions, to better understand psychological processes and the role of emotions in this decision-making, as well as to increase the effectiveness of marketing communication, such as advertising or product placement, all through the analysis of neurobiological determinants."

These definitions, although they provide a relatively specific picture of the scope of neuromarketing, are not complete. The range of neuromarketing research covers a wider scope than these definitions cover. We therefore lean towards the most appropriate definition in Lee et al. (2007) study [3], which generally and briefly characterizes neuromarketing as a discipline that applies neuroscientific methods to analyze and to understand human behavior in relation to markets and market exchanges.

The adjacent conceivable neurobiological explanation begins at the basic level of neural connections, which are the simplest measurable elements of behavior. In this regard, in analogy to the goal of neuroscience, the goal of the neuromarketing can be understood as providing a complete theory explaining consumer behavior at the neural level. Using neuroscientific methods, neuromarketing seeks to reconstruct the process that leads a person from the initial perception of the stimulus to the final market activity [11].

On the contrary, it is appropriate to distinguish the term very closely related from neuromarketing, namely consumer neuroscience. In the literature, terms are often confused, but some authors, such as Hubert and Kenning (2008) [7] or Plassmann et al. (2012) [12] distinguish it from neuromarketing based on its motives: while consumer neuroscience is conducted by academics to better understand consumer behavior, neuromarketing aims to use this knowledge in managerial practice. However, even commercial subjects can monitor academic findings and take over some of them, and so neuroscience about consumers also undoubtedly fully fits into this work.

The original ideas for linking marketing and measuring human biological processes date back to the 1980s [13]. They were further developed in the 1990s with specific proposals for linking neuroimaging techniques and marketing, confirms Wilson et al. (2008) [14]. The first marketing company to offer neuromarketing technology, the American BrightHouse ${ }^{\circledR}$, was founded in 2001 , after which the field began to attract more attention in business, science and the media.

The term neuromarketing was first introduced in 2002 by Smidts [15]. What aroused interest in the use of neuroscientific methods in marketing? For decades, marketers have relied on traditional research techniques, experiments, questionnaires, and group discussions to measure consumers' desires, needs, and moods. However, the results of these measurements often did not fully explain the situation in which the researcher found himself. This is confirmed by Zaltman's observation [16] that there is a large gap between what consumers think and the methods that marketers use to collect this data. One of the possible explanations for this situation was the influence of unconscious mechanisms, which is very difficult, if not impossible to detect by classical techniques [17]. As we have already mentioned, cognitive science has confirmed that the vast majority of human decision-making takes place on an unconscious level, as confirmed by Damasio (2000) and Calne (2000) [4, 5]. But other factors also played a role in the rise in the demand for neuromarketing. From the end of the twentieth century in particular, the Western economy in particular has gradually developed into globalized world trade. This has led to an unprecedented excess of the supply over the demand in many sectors, and thus to pressure to better process the products on offer. The expansion of the newly ubiquitous marketing communication has made it more difficult to elaborate commercial messages to target recipients. The budgets of marketing departments also increased. Neuroscience has also advanced rapidly in its knowledge, and the medical techniques it uses have become more accessible. Neuromarketing thus promised to contribute to the solution of the mentioned problems, while other parameters of the situation facilitated its development. 
Another step that significantly contributed to the publicity and subsequent expansion of neuromarketing was the well-known study, discussed in more detail below, by McClur et al. (2004) [18] on influencing the experience of consuming sugary drinks by realizing their brand [10].

Hubert and Kenning (2008) [19] demonstrate the further development of neuromarketing by measuring the number of results in the search for the word neuromarketing by the Internet search engine Google®. While in 2004 the results were still in the thousands, in 2005 they exceeded 100,000, in the following year already 400,000 and in 2008 they reached 800,000 results. Javor et al. (2013) [2] these results complement the year 2012, when the same process produced $1,400,000$ results. Although this method is certainly not exact evidence, it at least gives an idea of the growing interest in neuromarketing.

Further technological progress leading to the increased speed, efficiency and portability of sophisticated neuroscientific devices has brought the exponential growth of marketing companies offering neuromarketing products, confirm Hubert and Kenning (2008) study [19]. Plassmann et al. (2012) [12] talk about more than 150 such companies. In the Czech Republic, marketing agencies provide similar services, in 2012 they were Confess, Ipsos Tambor, GfK and Millward Brown cites [20]. According to many authors, the main results of neuromarketing are yet to come. For all of them, Achrol and Kotler's (2012) talked about the clearly connected future of the science of consumer behavior and methods of biological cognition of its course [21].

\section{3-1- Neuromarketing Techniques}

The functioning of the brain, as mentioned, depends on the interaction of neurons carried out by electrochemical processes. The techniques used by neuroscience to capture these energy-intensive exchanges can be divided into those that measure them directly by observing changes in the electric and magnetic fields of the brain (EEG, MEG and TMS), and those that measure them indirectly by capturing their metabolic manifestations manifested by energy expenditure. (PET, fMRI, biometric methods):

- Electroencephalography (EEG) measures the simultaneous electrical activity of many neurons in the brain using electrodes placed on the subject's head. The number of electrodes used varies (usually from 16 to 256), which changes the accuracy of the measurement [22]. EEG is a non-invasive, portable, relatively comfortable and quiet technique, state Plassmann et al. (2007) [23] study. It can thus be assumed that it has a smaller impact on influencing the experiences of the subject. Thanks to its portability, it can be used, for example, in environments where the subject normally undergoes the researched activity. EEG is also relatively cheap, the device can be purchased for less than 10,000 USD [24]. It also provides very good time resolution of brain processes, normally capturing them every 1 millisecond to 3 milliseconds, according to Plassmann et al. (2007) [23] study. The disadvantage of EEG is poor spatial resolution, typically around one centimeter, and the inability to capture the activity of neurons located other than perpendicular to the lateral side of the brain [22]. The most appropriate use of EEG is to investigate where brain activity in the perception of marketing messages takes place on the right-left spectrum of the brain. Activity in the right part of the brain is associated with a higher emotional impact or with the desire to interact with the object, and thus offers the possibility of using it to measure the emotional impact of the advertising [24].

- Magnetoencephalography (MEG). It is based on the measurement of changes in the magnetic field induced by neural activity [22]. MEG offers much better spatial resolution than EEG, due to the lower influence of magnetic fields by the skull; it retains the same advantages of temporal resolution and is non-invasive. On the other hand, due to the need for very sensitive instruments, it is necessary to perform measurements in a magnetically isolated room, where large magnetometers are placed around the subject's head. As a result, this method is much more expensive, the purchase price of the devices is around 2,000,000 USD [24]. Another disadvantage is the unnatural environment, which can affect the measurement results. Roullet and Droulers (2010) [25] suggest the use of MEG to examine purchasing decisions.

- Transcranial magnetic stimulation (TMS) is not intended to study, but to alter the brain activity. Using the electromagnetic induction induced by a coil attached to the head, it induces a magnetic field that causes changes in the brain activity through the skull. These changes either induce the brain activity or, on the contrary, suppress it, tah is confirmed by Zurawicki (2010) study [26]. TMS is thus useful for drawing the conclusions about which parts of the brain are effective in given thought processes and what role they play in them. However, applicability is limited by a range of only 1 to 2 centimeters to the depth of the brain.

Indirect measurement consists in the monitoring of the metabolic processes related to neural activity. The basic idea here is that different mental activities are controlled in different parts of the brain, and that these sites can be identified by capturing changes in energy consumption, signalled by loss of glucose or oxygen [23].

- Positron emission tomography (PET) measures the consumption of glucose, oxygen and the binding of the neurotransmitters. At the beginning of the process, the subjects receive an injection of a radioactive substance, the 
isotopes of which bind to the mentioned elements and thus allow them to be measured. PET provides accurate results and data very useful for drawing conclusions about the functioning of psychological processes [22], but it is invasive, so its use in neuromarketing is somewhat limited [23].

- Functional magnetic resonance imaging (fMRI) is widely used in neuromarketing studies. Its most used method is BOLD (blood oxygen level-dependent), which is based on the capturing changes in the oxygenation of blood flowing in the brain. The premise is that the active parts of the brain consume the oxygen contained in the fresh blood that flows into them. Indeed, protons in oxygen-bound hemoglobin react differently with the induced magnetic field than those to which oxygen is not bound, as cited in Sanders (2009) study [27]. This interaction is measured by magnetic resonance imaging (MRI), the variation of which, which captures changes over time, is called functional [22]. fMRI provides high spatial resolution even in the deeper parts of the brain, typically on a scale of 1 to 3 millimeters [23]. It therefore provides quality data to localize the neural activity. Furthermore, it is non-invasive, thus offering the possibility of repeated experiments with the same subjects [22]. On the other hand, fMRI has poor time resolution, scanning the brain only every five to eight seconds. Furthermore, the measurement takes place in an unnatural environment for the test subject, as the subject must lie down, surrounded by a noisy device, strictly motionless throughout the scanning period [23]. fMRI is also more expensive compared to other techniques, due to the purchase price of approximately 1,000,000 USD for Tesla (the quality of the devices depends on this capacity) [24]. The use of fMRI may involve examining the subjective value or relationship to the brand experienced [25]. This technique is often applied in neuromarketing research, and we can expect a further increase in the expected technological improvement to make fMRI usable in more natural environment, such as sitting [26]. Some authors question the reliability of fMRI. In a well-known study by Bennett et al. (2009) [28], they made an extremely attractive discovery when examining the brain activity of Atlantic salmon. When asked to evaluate human emotions in pictures, they used fMRI to measure activity in his brain, confirming that it was indeed able to judge human emotions. But the salmon was already dead. Bennett et al. (2009) [28] demonstrated the unreliability of fMRI measurements. They therefore call for a thorough verification of all the results of this technique. The fMRI also questions the repeatability of the results and the fact that the movement of blood in the brain (measured by the BOLD method) tells about all brain processes [27].

For completeness, it should be added that recent indirect technique is near infrared spectroscopy, which collects data using infrared radiation and offers a good ratio of quality of results and invested price [25].

- Biometric techniques: When analyzing the techniques used by neuromarketing, it is important to recall even the more classical ones, consisting in the direct monitoring of physiological processes and changes.

- Measurement of eye movements. This method consists in monitoring what the subject is looking at, how long he has been looking at the given stimulus and how he got there, and also in measuring the enlargement of the pupils. The moments of relative immobility of the eyes are called fixation, rapid movements of the saccade eyes or saccadic movements [29]. The measurement of eye movements can be used, for example, in the analysis of the focus of attention when displaying advertisements, websites or at the point of sale [26].

- Measurement of physiological processes, such as heart rate, blood pressure, reaction time, cortisol hormone level (stress-related), galvanic resistance of the skin (affected by sweating) or capturing camera movements of mimic muscles, followed by the evaluation of experienced emotions using computer programs (face reading). These reactions indicate the emotional experiences of the subject.

If we summarize the differences between the mentioned techniques, we state that each of them, thanks to its advantages and disadvantages, offers different possibilities of use. Therefore, one of them cannot be declared the most suitable for the neuromarketing research without significant simplification.

To illustrate, Hubert and Kenning (2008) state "there are up to 100,000 neurons per square millimeter of brain surface, and for example, fMRI, a method with good spatial resolution, contains data from about 55 cubic milimetres of brain, which contains 5,500,000 neurons or 220 kilometers of axons, protrusions of neurons" [19]. After considering this complexity of the brain, it is clear that the most accurate predictive value will be those researches that use a combination of techniques, benefiting from the advantages of each.

\section{4- Results and Discussion}

Conceptually, the practical uses of neuromarketing can be divided into two groups. The first consists of methods application leading to the optimization of marketing communication. The second is the use of neuromarketing research to find out specific knowledge about the needs or wishes of the consumer or his perception of the product. 


\section{4-1- Optimization of Marketing Communication}

The use of neuromarketing in relation to the marketing communication mainly concerns the optimization of the advertisements, brand management or communication at the point of sale:

- Advertising: According to Ariely and Berns (2010) [24] study, the majority of neuromarketing practice has so far focused on measuring the effectiveness of advertising. According to Zurawicki (2010) [26] study, neuromarketing provides data on three categories of impacts of advertising perception on consumers. The first is the valence of the emotional response, i.e. if the subject perceives the advertisement emotionally or negatively. The second represents the degree of involvement (arousal), or the intensity of the feelings experienced. The third describes the degree of involvement of cognitive processes, including focusing attention on information in advertising, or how they pass into memory.

Ohme et al. (2009) [31] give example of the use of neuromarketing in connection with television advertising as well. In the research, they tested two versions of advertising that differed from each other in only one five-second scene, which was not consciously assessed by the subjects as important. The use of conventional marketing techniques has shown that both ads were ranked almost identically. However, neuromarketing research using EEG and measuring the galvanic resistance of the skin showed a significant difference in the effectiveness of both ads, and based on it, it was possible to clearly recommend the use of one of them.

Other possibilities of using neuromarketing are offered in print, outdoor or internet advertising. We will give an example of the so-called heatmap, which uses cameras measuring eye movements to monitor which points the subject looks at while watching the advertisement.

- New media: Similar to the previous example of using a heatmap for print ads, eye movement measurement is also used to optimize the websites. The findings are important for the correct setting of the user environment, especially for the visitor to be guided through the site to the intended places without unnecessary losses and thus perform the desired actions. Adhami (2013) [33], for example, tested three mobile applications for online shopping in EEG research and eye measurement. In addition to identifying problem areas in the user environment of the purchasing process, such as too large product offerings leading to a loss of user interest, the findings included that the user's product selection depends significantly more on images than on text descriptions. Furthermore, the EEG was used, contrary to what the subjects explicitly stated in the questionnaires, that the most positive emotional involvement does not come when choosing products, but after paying for them. For example, it is recommended to direct the user's attention to the brand at this later stage. Neuromarketing research also provides other insights into new media. For example, McRae (2013) [34] suggest that consumers experience stronger emotional experiences when visiting a website from a mobile device compared to visiting from a desktop computer. This finding may therefore justify paying more attention to communication on these platforms, or a greater focus on mobile devices when scheduling the marketing budget for online advertising, especially for companies that emphasize this communication channel.

- Point of sale: Shopping at the point of sale is governed primarily by the habits of shoppers [35]. To increase the market share, consumers need to be led out of these habits, which can best be achieved through their emotional involvement. The study of this connection is possible mainly by the use of EEG due to its easy portability and relatively low degree of disturbance of the normal environment. Moreover, ensuring a certain degree of satisfaction throughout the purchasing process is more important than focusing unconditionally on the product itself [32], and so using the data obtained by neuromarketing methods to adapt the environment has a great potential effect on the overall product market performance. In addition, however, neuromarketing studies consumer behavior at the point of sale. In doing so, it addresses, for example, the processes by which the consumer seeks products or the question of what influences his decision at the point of sale. Reutskaja et al. (2011) [36] examined the effect of the quantity of the products offered, as well as the effect of their placement on the shelves, on their sales. Among other things, they found that shoppers tended to look first at products located in the middle of all exhibits, and that products placed in this way sold the most. For example, a sample of 9 products was $60 \%$ more likely to buy products located in the middle than products located elsewhere. The actual distribution of products at the point of sale thus significantly affects their sales and its correct setting can play a significant role.

\section{4-2- Researches}

Another area of the use of neuromarketing is in marketing research testing products or finding out the data about the target group and its preferences. These are carried out mainly before the products are placed on the market. They provide better capabilities to predict the product success, as well as more efficient resource allocation.

- Product: There is a great potential for the use of neuromarketing in testing products before they are placed on the market in order to improve them on the basis of the acquired knowledge. Ariely and Berns (2010) [24] identify the main areas of the neuromarketing research related to the product development. They are the food and entertainment 
industry, architecture and politics. In addition to the products themselves, neuromarketing also examines their packaging [37]. An example of its use can be demonstrated in research [38]. In it, the reactions of a relatively small sample of subjects when listening to songs by mostly unknown artists were tested using fMRI. Based on the identification of activated parts of the brain during listening, assumptions were made about the success or failure of the songs, often in conflict with the stated subjective experience of the tested persons. It turned out that the estimated sales values of the songs in question corresponded significantly to their real sales, which were calculated after three years of their availability on the market. Research thus suggests that neuromarketing testing of products prior to their introduction indicates not only the subjective evaluation of the product by the person being examined, but that the results can also be generalized and, as a result, estimate whether the product will be successful.

- Segmentation and positioning: Zurawicki (2010) [26] divides the relationship between neuromarketing, segmentation and market positioning into two groups. The first contains general demographic knowledge, according to which it is possible to better segment the market. They offer findings on the different functioning of the cognitive and affective processes of people divided mainly by gender or age. The second relates to more specific knowledge, depending on the focus of the company. It contains a division of the target groups based on the shopping behavior, the style of their decision-making or the degree of their openness to communication stimuli. An example of its application is research made by Neff (2012) [39], which, based on an EEG study, presents the idea that generations of people born during economic prosperity in the US after World War II (baby boomers), compared to other population groups, perceive complex visual and verbal information more difficult and that they experience fewer negative experiences when perceiving advertisements. Based on this finding, a company that targets this generation could adjust its marketing communications to simpler, more frequent communications.

Due to the use of medical neuroscience methods for marketing purposes, the ethics of neuromarketing is discussed in the media, in the professional and non-professional circles. We will first describe the opponents' arguments. These focus mainly on issues of consumer free will and protection of his privacy.

The first argument mentioned is based on the assumption that neuromarketing tries to find a "buy button" in the consumer's brain, after which the consumer will buy the products automatically. Proponents of this view argue that neuromarketing does not aim to inform about the product, but primarily to use emotions and other partially or completely unconscious processes in the consumer's mind to persuade them to buy the product. If this ability of neuromarketing reaches a critical degree of effectiveness, according to Wilson et al. (2008) or Murphy et al. (2008) [14, 40], it will pose a threat to the free, logical and informed consumer decision-making.

The second emerging argument against the ethics of neuromarketing is the one describing the threat to the privacy of the subjects [41]. The brain is the center of the human personality and its successful study can lead to its full knowledge. Already now, when examining the reactions to various advertisements, the courts of the examined persons about the age, gender or skin color of the persons appearing in these advertisements are accessible to researchers. Another problem is that there is a risk of sales or leaks of this particularly private data for other commercial and noncommercial purposes. Among other things, for example, accidental findings of pathological phenomena in the brains of the subjects, which occur in 1 to $2 \%$ of cases, are potentially interesting for insurance companies [42].

In addition to these two, there are other arguments against the ethics of neuromarketing, which also apply to marketing as such. These include, for example, criticisms of the use of neuromarketing by companies selling tobacco or alcohol products. Opposing these views are arguments highlighting the benefits of neuromarketing.

The first is the claim that neuromarketing provides better understanding of the consumer, his/her wishes and needs, to which companies subsequently adapt. As a result, according to this opinion, neuromarketing brings greater consumer satisfaction [14]. Furthermore, neuromarketing in the application of knowledge about attention or preferences can lead to less frequent use of shock tactics or images with sexual motives in marketing communication, as it allows you to know what attracts the audience better. It can also lead to better targeting of advertisements and thus greater relevance to the interests and experiences of consumers [3]. In addition, by better understanding some of the negative effects of advertising, it can reduce, for example, unnecessary compulsive consumption.

To summarize this chapter, we state that the views of the most vocal opponents of neuromarketing often stem from a misunderstanding of its current state or an exaggeration of its possibilities. The public and the media overestimate the results of neuromarketing [40]. So far, it can be said that neuromarketing in itself does not endanger the free will of the consumer, and from an ethical point of view, so much is fine as the whole of marketing. As for the future, Murphy et al. (2008) [40] propose to adopt a code of ethics for further safe development of the industry.

\section{4-3- Results of Questionnaire Survey}

Although neuromarketing is primarily intended for the use in the commercial sphere to streamline the targeting of the final product and thus to streamline its marketing communication, we state that its methods and techniques can be used in the educational process as well. This was already processed in the conditions of the Czech Republic and the 
outputs have been published in important database periodicals and presented at major world scientific forums. Examples are Škrabánková (2016) [43], Škrabánková and Trnová (2014) [44], Škrabánková et al. (2018) [45] and Škrabánková et al. (2015) [46] or Gabrhelová et al. (2020) [56].

We are therefore convinced that the area of education, training or work with gifted pupils can be one of the key areas that can make full use of the potential and possibilities of neuromarketing in the event that a Neuromarketing Center is established in the Czech Republic. Its services could be fully used to optimize the teaching process and to research the application of primarily activating teaching methods at all levels of education. There is a premise that education services would also have a cross-border dimension and thus a positive impact on the reputation and economy of the agglomeration where the Neuromarketing Center would be run.

The results of the questionnaire survey clearly showed that there is a clear interest in the services of the Neuromarketing Center in the Olomouc agglomeration.

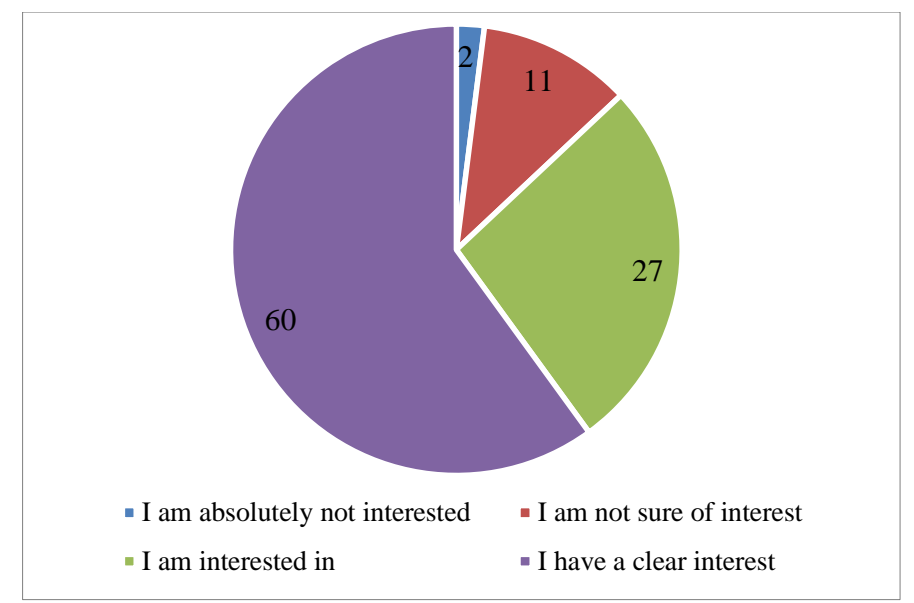

Figure 2. Expression of the overall interest of the respondents from the Olomouc agglomeration in the services of the Neuromarketing Center.

Figure 2 expresses the results of respondents' interest in the services of the Neuromarketing Center.

Table 3 Expression of the overall interest of the addressed respondents from the Olomouc agglomeration in the services of the Neuromarketing Center according to individual CZ-NACE and the degree of interest

\begin{tabular}{|c|c|c|c|c|c|c|c|}
\hline $\begin{array}{l}\text { Section } \\
\text { name }\end{array}$ & CZ-NACE & $\begin{array}{l}\text { Number of } \\
\text { respondents }\end{array}$ & Share & $\begin{array}{c}\text { Absolutely } \\
\text { not }\end{array}$ & $\begin{array}{l}\text { I am not } \\
\text { sure }\end{array}$ & $\begin{array}{c}\text { I am } \\
\text { interested }\end{array}$ & $\begin{array}{l}\text { Definitely } \\
\text { yes }\end{array}$ \\
\hline \multirow{3}{*}{ Industry } & Mining and quarrying & 5 & 0.2 & 4 & 1 & 0 & 0 \\
\hline & Manufacturing industry & 288 & 15.5 & 1 & 2 & 98 & 187 \\
\hline & $\begin{array}{l}\text { Production and distribution of electricity, } \\
\text { gas and water }\end{array}$ & 2 & 0.1 & 1 & 1 & 0 & 0 \\
\hline Construction & Construction & 208 & 11.2 & 1 & 3 & 116 & 88 \\
\hline Trade & $\begin{array}{l}\text { Trade, repair of motor vehicles and products } \\
\text { for other consumption and mainly household }\end{array}$ & 472 & 25.7 & 5 & 14 & 35 & 418 \\
\hline Hospitality & Accommodation and meals & 78 & 4.2 & 3 & 0 & 52 & 23 \\
\hline Transport & Transport, storage and communications & 71 & 3.8 & 5 & 0 & 62 & 4 \\
\hline Finance & Financial intermediation & 32 & 1.7 & 2 & 2 & 22 & 6 \\
\hline \multirow{5}{*}{ Services } & $\begin{array}{l}\text { Real estate and renting activities, business } \\
\text { activities }\end{array}$ & 65 & 3.5 & 1 & 18 & 26 & 20 \\
\hline & $\begin{array}{l}\text { Public administration and defense, } \\
\text { compulsory social security }\end{array}$ & 1 & 0.05 & 1 & 0 & 0 & 0 \\
\hline & Education & 98 & 5.3 & 4 & 1 & 25 & 68 \\
\hline & Health and social care, veterinary activities & 9 & 0.5 & 5 & 4 & 0 & 0 \\
\hline & Other public social and personal services & 524 & 28.2 & 0 & 158 & 65 & 301 \\
\hline \multirow{2}{*}{ Agriculture } & Agriculture, hunting, forestry & 4 & 0.02 & 4 & 0 & 0 & 0 \\
\hline & Fishing and angling & 0 & 0 & 0 & 0 & 0 & 0 \\
\hline Total & & 1857 & 100 & 37 & 204 & 501 & 1115 \\
\hline
\end{tabular}




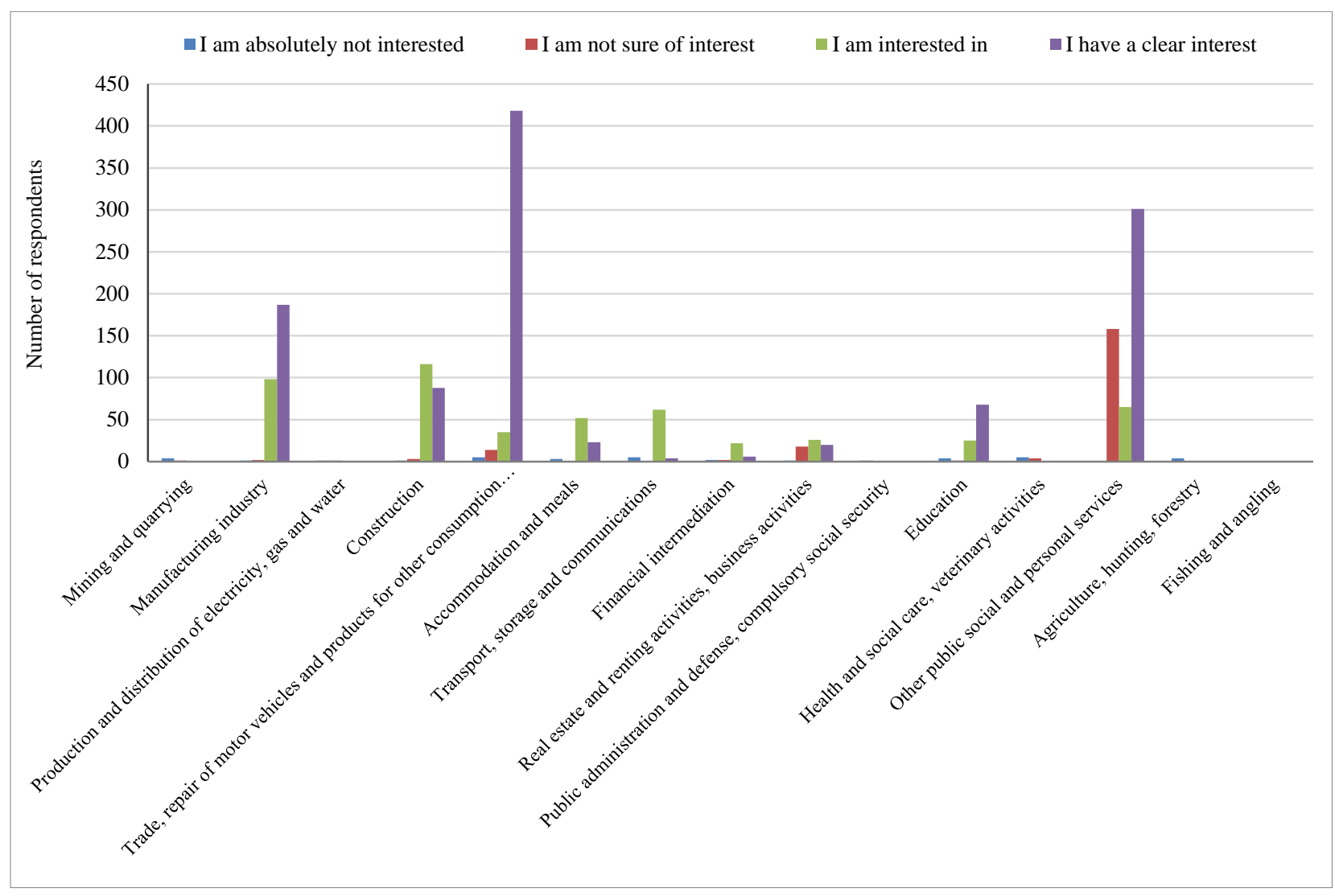

Figure 3. Graphic expression of the overall interest of the addressed respondents from the Olomouc agglomeration in the services of the Neuromarketing Center according to individual CZ-NACE and level of interest.

Neuromarketing is a useful tool with a relatively large potential. Therefore, we are convinced that the existence of the Neuromarketing Center in the ITI of the Olomouc agglomeration will be a significant contribution to the development of the region's economy, not only by creating new jobs but also by increasing the mental standard, developing higher living standards and overall life satisfaction.

\section{5- Conclusions}

Neuromarketing combines the strictly professional discipline of the neuroscience with the marketing, which goals and means are often questioned with the reference to its impact on individuals and society. This is one of the reasons why neuromarketing is media-attractive, and the media's interest in reporting on this phenomenon often does not lead to an objective view, but to maximize the readability of the article. If a reader interested in neuromarketing wanted to learn more, he would probably come across a similar approach in the Czech literature, where popularization titles would promise to look into the minds of consumers and to find a "shopping button" in them. One of the aims of the presented paper was to provide an alternative to this scenario. On the way to interpret the objective picture of the current state of neuromarketing, the work first defined the concepts, then discussed the history and techniques, the main theoretical areas and ways of practical use, and finally the ethical question.

We state that neuromarketing is a discipline that applies neuroscientific methods to analyze and to understand human behavior in relation to the markets and market exchanges. It has a relatively short history. Its roots go back to the 1980 s, but its main development, related to the global economic situation, did not begin until 2004. Each of the neuromarketing techniques measures different data and suits different purposes, with a combination of the most reliable results. The interest in the theoretical research of neuromarketing focuses on the consumer decision-making process, which he examines primarily by means of functional magnetic resonance imaging. Consumer decision-making is most often made on an unconscious level using emotion-based rating systems. Neuromarketing provides unique insight into this decision.

The acquired theoretical knowledge can be used in practice with the correct application, as shown in the examples, with almost zero costs. In addition, neuromarketing is particularly useful in optimizing ads and testing the products before they are released. To do this, it mostly uses the electroencephalography and biometric methods, techniques available, inexpensive and easily compared with others. In contrast, other techniques, such as fMRI, are relatively difficult, expensive to apply to specific cases, and their use does not yet provide sufficient added value to commercial companies. Even in practical use, the main benefit of neuromarketing is data that cannot be determined by conventional marketing techniques, or at least it is very difficult. 
From an ethical point of view, neuromarketing is currently fine to the same extent as marketing itself.

At this point, it should also be said that neuromarketing does not offer a magical solution for marketing departments. Criticism of neuromarketing includes questioning the functionality of the technologies themselves, which states Sanders (2009) [27], and Bennett et al. (2009) [28], the accuracy of data acquisition (such as sample size), their application, interpretation and repeatability [47], Kaye (2013) [48], Wardlaw (2011) [49], McDowelll et al. (2013) [17] and Walvis (2008) [50] or Egidi et al. [22].

By selecting relevant publications [52-55] the vast majority of which came from foreign professional periodicals, identifying their main topics and then combining the knowledge contained in them, we aimed to provide a comprehensive interpretation of the concept of neuromarketing in terms of marketing communication. The intention was also to offer an objective, academic overview of the topic and its main areas of interest in Czechia, so that information will be available to readers in this language, at least in a limited form. We consider both goals to be fulfilled.

One of the main benefits of neuromarketing is the potential to measure accurate, objective data that can be used to make informed decisions in management practice. However, it is currently only a complement to other areas of marketing and will be beneficial if it is used to obtain otherwise inaccessible data. In order for it to be unquestionably trusted, it has yet to come, among other things, through developments in the field of neuroscience.

\section{5-1- Limitations}

Due to the topic, this paper presents only secondary data. The necessary technologies for field research, and therefore for obtaining primary data, are not currently available to us. Most sources come from professional foreign, marketing, neuroscience or psychological periodicals. These sources are more suitable than the already mentioned insufficient Czech written literature, because they provide more related information, given that research and professional articles by leading researchers in the field are published in this way.

\section{6- Declarations}

\section{6-1-Data Availability Statement}

The data presented in this study are available in article.

\section{6-2-Funding}

This work was supported by the IGA VŠDTI č. 007/2019 provided by the DTI University, Dubnica nad Váhom, Slovakia.

\section{6-3- Conflicts of Interest}

The author declares that there is no conflict of interests regarding the publication of this manuscript. In addition, the ethical issues, including plagiarism, informed consent, misconduct, data fabrication and/or falsification, double publication and/or submission, and redundancies have been completely observed by the authors.

\section{7- References}

[1] O'Connell, Barbara, Steven Walden, and Andrew Pohlmann. "Marketing and neuroscience what drives customer decisions." American Marketing Association. (2011).

[2] Javor, Andrija, Monika Koller, Nick Lee, Laura Chamberlain, and Gerhard Ransmayr. "Neuromarketing and Consumer Neuroscience: Contributions to Neurology.” BMC Neurology 13, no. 1 (February 6, 2013). doi:10.1186/1471-2377-13-13.

[3] Lee, Nick, Amanda J. Broderick, and Laura Chamberlain. "What Is 'neuromarketing'? A Discussion and Agenda for Future Research.” International Journal of Psychophysiology 63, no. 2 (February 2007): 199-204. doi:10.1016/j.ijpsycho.2006.03.007.

[4] Damasio, Antonio R. Descartesův omyl: emoce, rozum a lidský mozek. Mladá fronta, (2000).

[5] Calne, Donald. Within reason: Rationality and human behavior. Vintage, (2000).

[6] "Brain Scam?” Nature Neuroscience 7, no. 7 (July 2004): 683-683. doi:10.1038/nn0704-683.

[7] Hubert, Mirja, and Peter Kenning. “A Current Overview of Consumer Neuroscience.” Journal of Consumer Behaviour 7, no. 45 (July 2008): 272-292. doi:10.1002/cb.251.

[8] Wilson, Timothy D., Douglas J. Lisle, Jonathan W. Schooler, Sara D. Hodges, Kristen J. Klaaren, and Suzanne J. LaFleur. “Introspecting About Reasons Can Reduce Post-Choice Satisfaction." Personality and Social Psychology Bulletin 19, no. 3 (June 1993): 331-339. doi:10.1177/0146167293193010.

[9] McDowell, Walter S., and Steven J. Dick. “The Marketing of Neuromarketing: Brand Differentiation Strategies Employed by Prominent Neuromarketing Firms to Attract Media Clients.” Journal of Media Business Studies 10, no. 1 (March 2013): 25-40. doi:10.1080/16522354.2013.11073558. 
[10] Marci, Carl D. "Minding the gap: The evolving relationships between affective neuroscience and advertising research." International Journal of Advertising 27, no. 3 (2008): 473-475.

[11] Glimcher, P. W. "Neuroeconomics: The Consilience of Brain and Decision.” Science 306, no. 5695 (October 15, 2004): 447452. doi:10.1126/science.1102566.

[12] Plassmann, Hilke, Thomas Zoëga Ramsøy, and Milica Milosavljevic. "Branding the Brain: A Critical Review and Outlook." Journal of Consumer Psychology 22, no. 1 (January 2012): 18-36. doi:10.1016/j.jcps.2011.11.010.

[13] Lee, Nick, Amanda J. Broderick, and Laura Chamberlain. "What is 'neuromarketing'? A Discussion and Agenda for Future Research.” International Journal of Psychophysiology 63, no. 2 (February 2007): 199-204. doi:10.1016/j.ijpsycho.2006.03.007.

[14] Wilson, R. Mark, Jeannie Gaines, and Ronald Paul Hill. "Neuromarketing and Consumer Free Will." Journal of Consumer Affairs 42, no. 3 (August 28, 2008): 389-410. doi:10.1111/j.1745-6606.2008.00114.x.

[15] Smidts, Ale. "Kijken in het brein: Over de mogelijkheden van neuromarketing." (2002).

[16] Zaltman, Gerald. How customers think: Essential insights into the mind of the market. Harvard Business Press, (2003).

[17] McDowell, Walter S., and Steven J. Dick. "The Marketing of Neuromarketing: Brand Differentiation Strategies Employed by Prominent Neuromarketing Firms to Attract Media Clients.” Journal of Media Business Studies 10, no. 1 (March 2013): 25-40. doi:10.1080/16522354.2013.11073558.

[18] McClure, Samuel M., Jian Li, Damon Tomlin, Kim S. Cypert, Latané M. Montague, and P.Read Montague. "Neural Correlates of Behavioral Preference for Culturally Familiar Drinks." Neuron 44, no. 2 (October 2004): $379-387$. doi:10.1016/j.neuron.2004.09.019.

[19] Hubert, Mirja, and Peter Kenning. “A Current Overview of Consumer Neuroscience.” Journal of Consumer Behaviour 7, no. 45 (July 2008): 272-292. doi:10.1002/cb.251.

[20] Huberová, Monika. (2012): Zájem o neuromarketing se zvyšuje. Marketing \& Media.

[21] Achrol, Ravi S., and Philip Kotler. "Frontiers of the Marketing Paradigm in the Third Millennium.” Journal of the Academy of Marketing Science 40, no. 1 (May 11, 2011): 35-52. doi:10.1007/s11747-011-0255-4.

[22] Egidi, Giovanna, Howard C. Nusbaum, and John T. Cacioppo. "Foundational Issues and Consumer Relevance." Marketing and Consumer Psychology Series: 1177, (2008).

[23] Plassmann, Hilke, Tim Ambler, Sven Braeutigam, and Peter Kenning. "What Can Advertisers Learn from Neuroscience?" International Journal of Advertising 26, no. 2 (January 2007): 151-175. doi:10.1080/10803548.2007.11073005.

[24] Ariely, Dan, and Gregory S. Berns. "Neuromarketing: The Hope and Hype of Neuroimaging in Business." Nature Reviews Neuroscience 11, no. 4 (March 3, 2010): 284-292. doi:10.1038/nrn2795.

[25] Roullet, Bernard, and Olivier Droulers. Neuromarketing: le marketing revisité par la neuroscience du consommateur. Dunod, (2010).

[26] Zurawicki, Leon. Neuromarketing: Exploring the brain of the consumer. Springer Science \& Business Media, (2010). doi:10.1007/978-3-540-77829-5.

[27] Sanders, Laura. "Trawling the Brain: New Findings Raise Questions about Reliability of fMRI as Gauge of Neural Activity." Science News 176, no. 13 (December 10, 2009): 16-20. doi:10.1002/scin.5591761320.

[28] Bennett, CM, MB Miller, and GL Wolford. "Neural Correlates of Interspecies Perspective Taking in the Post-Mortem Atlantic Salmon: An Argument for Multiple Comparisons Correction.” NeuroImage 47 (July 2009): S125. doi:10.1016/s10538119(09)71202-9.

[29] Nolen-Hoeksema, Susan, et al. "Psychologie Atkinsonové a Hilgarda." Praha: Portál (2012).

[30] Kenning, Peter. "What advertisers can do and cannot do with neuroscience." International Journal of Advertising 27, no. 3 (2008): $472-473$.

[31] Ohme, Rafal, Dorota Reykowska, Dawid Wiener, and Anna Choromanska. "Analysis of Neurophysiological Reactions to Advertising Stimuli by Means of EEG and Galvanic Skin Response Measures.” Journal of Neuroscience, Psychology, and Economics 2, no. 1 (2009): 21-31. doi:10.1037/a0015462.

[32] Suomala, Jyrki, et al. "Neuromarketing: Understanding customers' subconscious responses to marketing." Technology Innovation Management Review 2, no. 12 (2012): 12-21. doi:10.22215/timreview/634

[33] Adhami, Melody. "Using Neuromarketing to Discover How We Really Feel About Apps." International journal of mobile marketing 8.1 (2013).

[34] McRae, Eois, et al. "Want to be loved? Go mobile." International Journal of Mobile Marketing 8.2 (2013): 55-66.

[35] Vysekalová, Jitka. Emoce v marketingu. Praha: Grada Publishing, (2014). 
[36] Reutskaja, Elena, Rosemarie Nagel, Colin F Camerer, and Antonio Rangel. "Search Dynamics in Consumer Choice Under Time Pressure: An Eye-Tracking Study.” American Economic Review 101, no. 2 (April 1, 2011): 900-926. doi:10.1257/aer.101.2.900.

[37] Stoll, Marco, Sebastian Baecke, and Peter Kenning. "What They See Is What They Get? An fMRI-Study on Neural Correlates of Attractive Packaging.” Journal of Consumer Behaviour 7, no. 4-5 (July 2008): 342-359. doi:10.1002/cb.256.

[38] Berns, Gregory S., and Sara E. Moore. “A Neural Predictor of Cultural Popularity.” Journal of Consumer Psychology 22, no. 1 (June 8, 2011): 154-160. doi:10.1016/j.jcps.2011.05.001.

[39] Neff, Kristin D. "The science of self-compassion." Compassion and wisdom in psychotherapy 1 (2012): 79-92.

[40] Murphy, Emily R., Judy Illes, and Peter B. Reiner. "Neuroethics of neuromarketing." Journal of Consumer Behaviour: An International Research Review 7.4-5 (2008): 293-302. doi:10.1002/cb.252.

[41] EDITORIAL: Neuromarketing: Beyond Branding. The Lancet Neurology, (2004b).

[42] Rapp, Justine, Ronald Paul Hill, Jeannie Gaines, and R. Mark Wilson. "Advertising and Consumer Privacy." Journal of Advertising 38, no. 4 (December 2009): 51-61. doi:10.2753/joa0091-3367380404.

[43] Škrabánková, Jana. "Practical Use of the Eye Camera in Pedagogical Research (Processing of Selected Data Using the Eye Tracking Method).” Acta Technologica Dubnicae 6, no. 1 (June 1, 2016): 70-77. doi:10.1515/atd-2016-0001.

[44] Škrabánková, Jana, and Eva Trnová. "Researching Students Gifted in Science Using the Method of Eye Tracking." The 13th APFG Conference on Giftedness. Beijing: China. (2014).

[45] Škrabánková, Jana, Lukáš Laš, and Petr Bujok. "Visualisation and interpretation of student strategies in solving natural sciencebased tasks using the eye-tracker." Journal of Eye Movement Research 11.4 (2018): 4.

[46] Škrabánková, Jana, Josef Trna, and Eva Trnová. "Eye Tracking method in the research of mathematical and logical intelligence of students at primary school." (2015).

[47] Vul, Edward, Christine Harris, Piotr Winkielman, and Harold Pashler. "Puzzlingly High Correlations in fMRI Studies of Emotion, Personality, and Social Cognition.” Perspectives on Psychological Science 4, no. 3 (May 2009): 274-290. doi:10.1111/j.17456924.2009.01125.x.

[48] Kaye, Howard L. "Aping Mankind: Neuromania, Darwinitis and the Misrepresentation of Humanity." The Hedgehog Review 15.1 (2013): 92-95.

[49] Wardlaw, Joanna M., Garret O’Connell, Kirsten Shuler, Janet DeWilde, Jane Haley, Oliver Escobar, Shaun Murray, et al. “'Can It Read My Mind?' - What Do the Public and Experts Think of the Current (Mis)Uses of Neuroimaging?” Edited by Marcelo Hermes-Lima. PLoS ONE 6, no. 10 (October 4, 2011): e25829. doi:10.1371/journal.pone.0025829.

[50] Walvis, Tjaco H. "Three Laws of Branding: Neuroscientific Foundations of Effective Brand Building." Journal of Brand Management 16, no. 3 (December 28, 2007): 176-194. doi:10.1057/palgrave.bm.2550139.

[51] Page, Graham, and Jane Raymond. "Neuroscience and marketing: It's what it means that counts, not how it's done." (2007): 132134.

[52] Nilashi, Mehrbakhsh, et al. "Neuromarketing: A Review of Research and Implications for Marketing." Journal of Soft Computing and Decision Support Systems 7.2 (2020): 23-31.

[53] Brenninkmeijer, Jonna, Tanja Schneider, and Steve Woolgar. "Witness and Silence in Neuromarketing: Managing the Gap Between Science and Its Application.” Science, Technology, \& Human Values 45, no. 1 (February 14, 2019): 62-86. doi:10.1177/0162243919829222.

[54] Meyerding, Stephan G.H., and Clara M. Mehlhose. "Can Neuromarketing Add Value to the Traditional Marketing Research? An Exemplary Experiment with Functional Near-Infrared Spectroscopy (fNIRS).” Journal of Business Research 107 (February 2020): 172-185. doi:10.1016/j.jbusres.2018.10.052.

[55] Spence, Charles. "On the Ethics of Neuromarketing and Sensory Marketing." Organizational Neuroethics (November 28, 2019): 9-29. doi:10.1007/978-3-030-27177-0_3.

[56] Gabrhelová, Gabriela, Lenka Pasternáková, and Dáša Porubčanová. "The Occurrence of Problematic Behaviour in the School Environment.” SAR Journal - Science and Research (June 30, 2020): 59-64. doi:10.18421/sar32-02. 